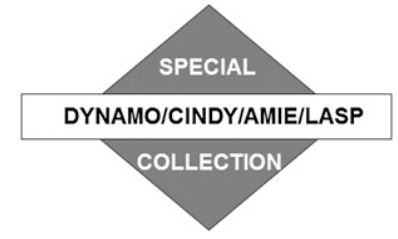

\title{
Observing Possible Thermodynamic Controls on Tropical Marine Rainfall in Moist Environments
}

\author{
SCOTT W. POWELL \\ Department of Meteorology, Naval Postgraduate School, Monterey, California
}

(Manuscript received 23 May 2019, in final form 3 September 2019)

\begin{abstract}
Radar and rawinsonde data from four ground-based observing stations in the tropical Indo-Pacific warm pool were used to identify possible associations of environmental state variables and their vertical profiles with radar-derived rain rate inside a mesoscale radar domain when the column-integrated relative humidity (CRH) exceeds $80 \%$. At CRH exceeding $80 \%$, a wide range-from near 0 to $\sim 50 \mathrm{~mm}^{-1 a y}{ }^{-1}$-in rain rate is observed; therefore, tropospheric moisture was a necessary but insufficient condition for deep convection. This study seeks to identify possible factors that inhibit rainfall when the atmosphere is sufficiently moist to support large precipitation rates. The domain-mean rain rate was highly sensitive to the areal coverage of intense, convective rainfall that occurs. There were two fundamentally different instances in which convective area was low. One was when the radar domain is primarily occupied by weakly precipitating, stratiform echoes. The other was when the radar domain contained almost no precipitating echoes of any type. While the former was dependent upon the stage of the convective life cycle seen by radar, the latter was probably dependent upon the convective environment. Areal coverage of convective echoes was largely determined by the number of individual convective echoes rather than their sizes, so changes in the clear-air environment of updrafts might have governed how many updrafts grew into deep cumulonimbi. The most likely environmental influence on convective rainfall identified using rawinsonde data was 900-700-hPa lapse rate; however, processes occurring on spatial scales smaller than a radar domain were probably also important but not investigated.
\end{abstract}

\section{Introduction}

Prediction of tropical precipitation is challenging. Over the oceans, rainfall is dependent upon a myriad of factors such as-and probably not limited to-upperocean and sea surface properties; atmospheric boundary layer wind, temperature, and humidity; clear-air freetropospheric thermodynamic and dynamic properties; and kinematic and microphysical characteristics of clouds, any of which may impact the others through nonlinear processes that are difficult to quantify. As a result, inadequate parameterization of the processes that lead to rainfall in numerical models is one bottleneck toward predictability of a wide array of tropical phenomena. Some parameterizations of cumuliform cloud populations require that atmospheric humidity reach a critical value before deep convection occurs (e.g., Song and Zhang 2009; Chikira 2010). This threshold is temperature dependent (Sahany et al. 2012; Kuo et al. 2017, 2018) and is used in

Corresponding author: Scott W. Powell, scott.powell@nps.edu models because rain rate is observed to sharply increase around a "critical" value of column-integrated relative humidity $(\mathrm{CRH})$, which is about $75 \%-85 \%$ (Derbyshire et al. 2004; Sobel et al. 2004; Peters and Neelin 2006; Muller et al. 2009; Wang and Sobel 2012; Kuo et al. 2018).

The relationship between $\mathrm{CRH}$,

$$
\mathrm{CRH}=\frac{\int_{P_{\mathrm{sfc}}}^{P_{\mathrm{top}}} q d P}{\int_{P_{\mathrm{sfc}}}^{P_{\mathrm{top}}} q_{\mathrm{sat}}(T) d P},
$$

and rain rate has been described as an exponential or power-law relationship (Bretherton et al. 2004; Ahmed and Schumacher 2015; Kuo et al. 2018; Rushley et al. 2018). In Eq. (1), $q$ is specific humidity, $q_{\text {sat }}$ is saturation specific humidity, $T$ is temperature, and $P$ represents pressure integrated from the ground or ocean to the top of the atmosphere-typically taken as the top of the troposphere. Empirical relationships relating the two variables 
have been derived using various satellite- and groundbased datasets. Modeling and observational studies have repeatedly shown that rainfall and/or vertical and horizontal extents of moist convection over tropical oceans is most sensitive to environmental water vapor (e.g., Alishouse 1983; Brown and Zhang 1997; Sherwood 1999; Raymond 2007; Redelsperger et al. 2002; Derbyshire et al. 2004; Holloway and Neelin 2009; Wang and Sobel 2012). Rain rate is most sensitive to water vapor concentrations beneath about $500 \mathrm{hPa}$. A nearsaturated upper-troposphere above $500 \mathrm{hPa}$ generally occurs where many cumulonimbi have already grown into deep convective elements and transported water upward (Sherwood and Wahrlich 1999; Sobel et al. 2004; Powell and Houze 2013). Generally, deep convection, including that which grows upscale into mesoscale convective systems, produces stronger vertical motions and higher rain rates than relatively weak shallow convection, although intense shallow updrafts do exist. Therefore, the same factors that control the depth of tropical marine convection also control tropical marine rain rate.

Over tropical oceans, where the subcloud boundary layer is often moist, one way free-tropospheric environmental air influences rain rate is by altering the buoyancy of updrafts emerging from the boundary layer. An updraft that entrains unsaturated environmental air becomes less buoyant; therefore, widespread, deep convection cannot occur in dry environments. If a buoyant updraft still possesses upward vertical velocity after moving through the low troposphere, it can grow into a deep, and possibly heavily precipitating, cumulonimbus cloud. For example, Holloway and Neelin (2009) proposed that tropical updrafts that are sufficiently buoyant to reach $500 \mathrm{hPa}$ are boosted by release of latent heat of fusion, which helps them to grow into deep convective elements that can reach the tropopause by also consuming ample convective available potential energy (from the perspective of a parcel lifted from near the surface) in the upper troposphere. Whether updrafts reach $500 \mathrm{hPa}$ depends on many factors, including not only low-tropospheric humidity, but also static stability (e.g., Mapes 2000; Raymond et al. 2003; Kuang 2008), boundary layer temperature and humidity and the magnitude of its eddy variability, and boundary layer convergence. Boundary layer characteristics may then be dependent upon other factors such as surface heat fluxes governed by sea surface temperature (SST) and near-surface wind. Raymond and Flores (2016) synthesized several of these factors into a two-dimensional model-derived empirical relationship that predicted mean rain rate over a 35-day period as a function of three variables: saturation fraction (essentially $\mathrm{CRH}$ ), moist entropy flux across the air-sea interface, and an instability index that accounted for temperature and humidity profiles below $7 \mathrm{~km}$. In their model, moist entropy flux from the ocean to atmosphere alone explained at least $69 \%$ of variance in rainfall. The modeled influence of processes at and near the air-sea interface on rainfall is not surprising, especially when considering Romps and Kuang (2011) concluding that approximately two-thirds of subcloud air transported into the free-troposphere originates within $100 \mathrm{~m}$ of the surface. However, when Raymond and Flores (2016) compared empirically predicted rainfall to observationally derived rainfall (using gridded dropsonde data to add moisture convergence to surface evaporation to estimate precipitation), the empirical prediction only accounted for $23 \%$ of variance in actual rainfall and overestimated the rainfall by a factor of 3 , highlighting the difficulty of predicting rainfall in the real atmosphere.

Ahmed and Neelin (2018), instead of examining just behavior of convective transitions with respect to water vapor, constructed the relationship between precipitation rate and buoyancy. By doing so, they considered how both low-tropospheric humidity and temperature impact vertical growth of convective updrafts. They found an exponential relationship between both boundary layer and lower-free-tropospheric equivalent potential temperature and rain rate. Tian and Kuang (2019), in an idealized model, also found that convective updrafts were more sensitive to temperature perturbations in the lower troposphere than in the upper troposphere. Schiro and Neelin (2019) recently concluded that shallow, isolated convection is largely dependent on boundary layer properties, but that convection organized on the mesoscale is impacted more by free-tropospheric moisture content than temperature. These results highlight the importance of humidity on upscale mesoscale growth of convection and further corroborate the hypothesis that low-tropospheric temperature exerts some control on convective depth and rain intensity for individual convective elements.

Given the sensitivity of convection to the freetropospheric temperature and boundary layer characteristics, that $\mathrm{CRH}$ is not an exact predictor of rain rate is not surprising. For example, Fig. 2 of Rushley et al. (2018) indicates that when $\mathrm{CRH}=0.8$, rain rate ranges from near 0 to about $50 \mathrm{~mm} \mathrm{day}^{-1}$. Unlike the model of Muller et al. (2009), in which variance of rainfall is less at very high values of CRH than at the critical value near 0.8 , the range of potential rainfall rates in observations is even larger when $\mathrm{CRH} \geq 0.8$. Similar spread in rain rate is illustrated using a completely different dataset later in this article (section 3). Visually, the lack of rainfall at high CRH can be illustrated through pictures of the 
cloud population during periods of moist conditions. For example, Fig. 1a shows a picture of shallow cumuli captured from the R/V Thomas G. Thompson over the Philippine Sea during the Propagation of Intraseasonal Tropical Oscillations (PISTON) field campaign at 0230 UTC 7 September 2018. Figure 1b shows the sounding launched from the ship near the same time the photo was taken. Total precipitable water (TPW) was $55.6 \mathrm{~mm}$, corresponding to $\mathrm{CRH}$ of $76.0 \%$. Despite fairly high CRH, satellite observations indicated that almost no deep convection was occurring within several hundred kilometers of the ship (Fig. 2). The golden circle near $9.7^{\circ} \mathrm{N}, 132.6^{\circ} \mathrm{E}$ encloses a $\sim 120-\mathrm{km}$ radius around the ship. Although not shown, microwavederived TPW exceeded $50 \mathrm{~mm}$ throughout virtually all of the large area over the Philippine Sea that was devoid of high clouds.

The large rain rates that do occur when CRH is above some critical value can likely be thought of as occurring during intermittent intense convective events associated with mesoscale convective systems. Tropical CRH at a point location has been shown to have a substantially longer autocorrelation time scale than precipitation (e.g., Fig. 1 of Holloway and Neelin 2010); therefore, the mere crossing of some critical value of environment CRH should not automatically signify heavy rainfall. Mapes et al. (2018) consistently acknowledged that high $\mathrm{CRH}$ is a necessary but insufficient condition for deep convection that occurs sporadically within tropical regions bounded by $\mathrm{CRH}$ that is approximately $80 \%$ or greater. Stochastic models of tropical convection (e.g., Stechmann and Neelin 2011; Frenkel et al. 2013) try to realistically represent the difference in autocorrelation time scales between rainfall and moisture, and heavy precipitation events in such models are essentially statistical noise occurring in a typical state of otherwise light or no precipitation, which is consistent with rainfall observations in the real atmosphere. However, simply attributing the highest observed tropical rain rates to pseudorandom variability is not a satisfying physical explanation for why such variability occurs. Other studies containing stochastic modeling components like Peters et al. (2013) conclude that variability in the modeled cloud fields were better predicted using quantities related to large-scale convergence. Their conclusions were corroborated with quantities derived from rawinsonde data near Darwin, Australia; however, persistent deep convection occurring over a large area also drives low-tropospheric convergence, and disentangling the cause and effect between deep convection and convergence is extremely difficult.

On large spatial scales, boundary layer convergence may be enhanced where SST gradients are large (Back
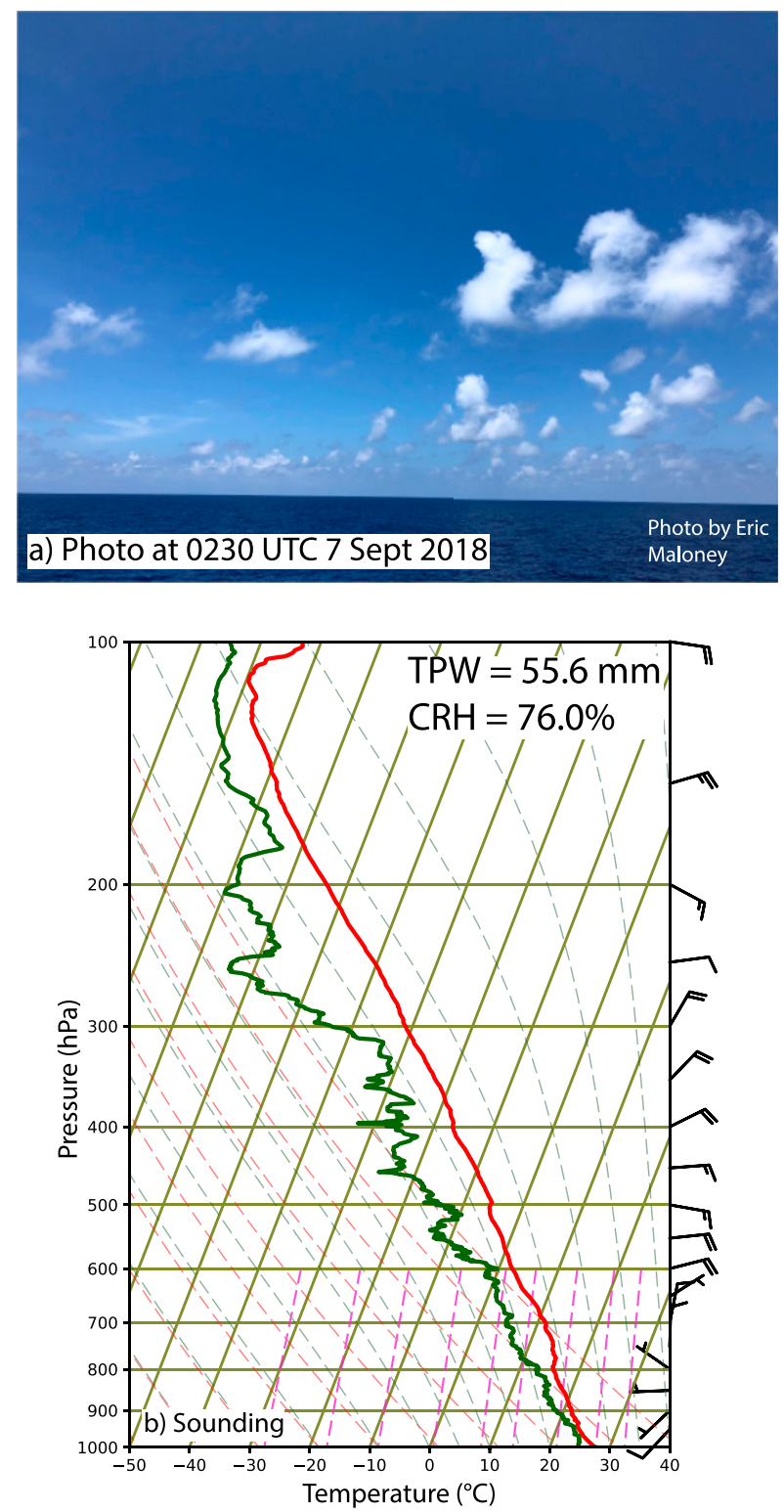

FIG. 1. (a) Photo of the cloud population near the R/V Thomas G. Thompson during PISTON at 0230 UTC 7 Sep 2018 (credit: Eric Maloney). (b) Skew $T-\log p$ plot for a sounding launched within a few minutes of the same time as the photo taken in (a). Values for TPW and CRH are listed in the top right.

and Bretherton 2009a,b). On long time scales, higher SST relative to the tropical mean supports larger daily rain rates (Wang and Sobel 2011). Additionally, while vertical wind shear may enhance precipitation in mesoscale convective systems (e.g., Moncrieff 1981; Liu and Moncrieff 2001; Anber et al. 2014), wind shear may reduce the intensity of young, shallow convective updrafts (Peters et al. 2019). Relationships of SST, SST gradient, and wind profiles with rain rate will be investigated in this article. 


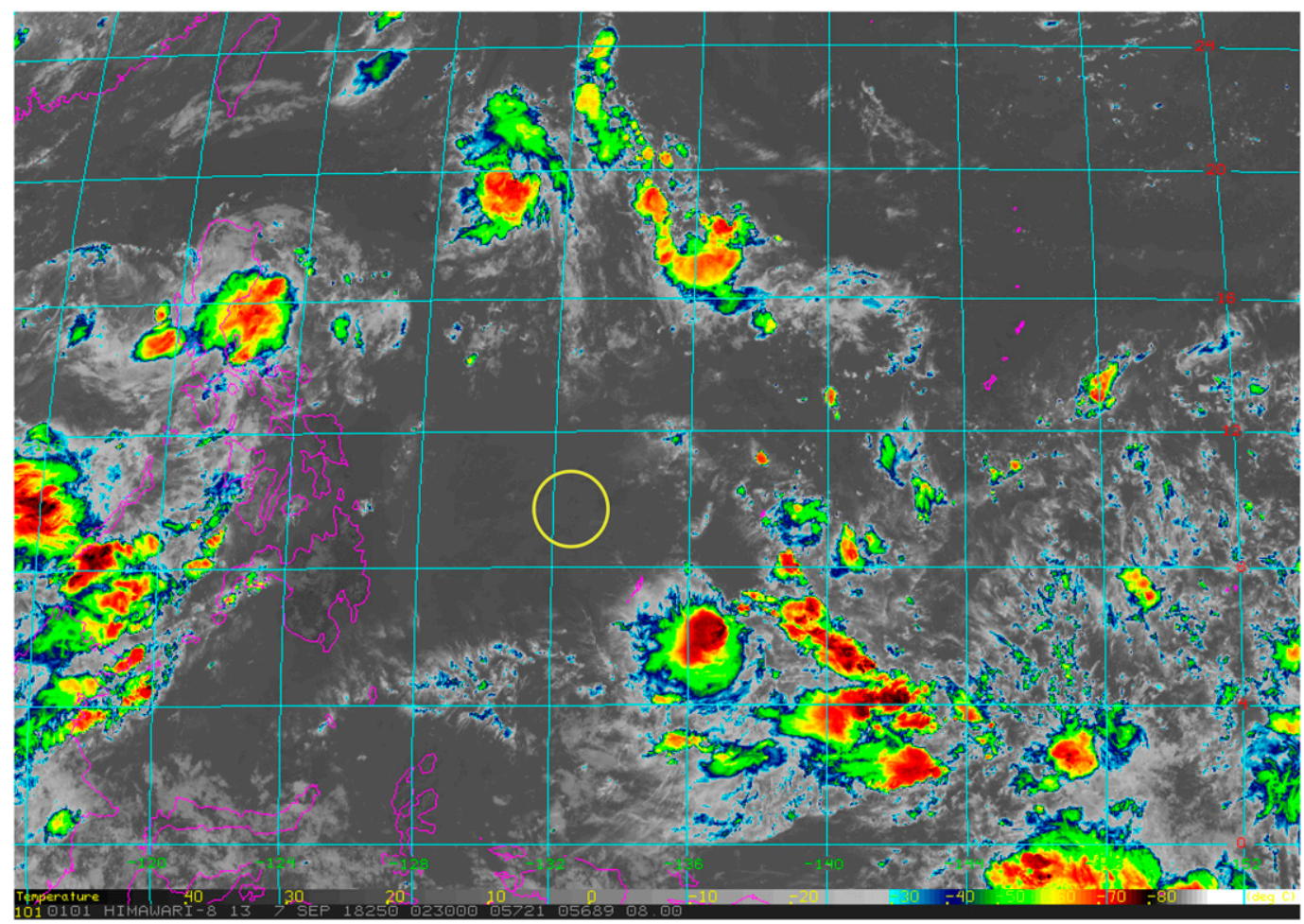

FIG. 2. Enhanced infrared $(10.3 \mu \mathrm{m})$ imagery over the Philippine Sea at 0230 UTC 7 Sep 2018. The golden circle encloses a 120-km radius around the approximate location of the ship and represents the approximate domain of the radar.

The underlying motivation for this study is to investigate why rain does not occur over tropical oceans even when one might expect rainfall given the moisture content of the atmosphere. The central hypothesis guiding this study is that some combination of environmental characteristics and/or sea surface properties (e.g., low-tropospheric lapse rate, vertical profiles of humidity, SST, SST gradient, wind shear, near-surface wind) determines whether shallow convection can actually grow into deep convection within a sufficiently moist environment. Thus, the primary objective is to use observations to determine what factors other than tropospheric water vapor content might impact tropical marine rain rate, and the analysis will be focused only on times during which CRH large enough to support widespread, deep convection occurred. While the question of what quantities impact growth of deep convection has been studied, analysis of observations with high spatial and temporal resolution and the exclusive focus on high CRH scenarios makes this work unique. This is merely an associative and elementary study, however, because we will only investigate the concurrence of high rainfall and environmental features such as low-tropospheric lapse rate, which proves nothing definitively about what processes actually cause and inhibit rain.

\section{Data}

Radar and rawinsonde data from four locations over the Indian and Pacific Oceans were utilized: Addu City, Maldives, and the Research Vessels Mirai and Roger Revelle all collected during the Dynamics of the Madden-Julian Oscillation (DYNAMO; Yoneyama et al. 2013) field campaign and archived at UCAR (2017); and Kwajalein Atoll (NASA 2014; NOAA/ESRL 2009). All locations were/are situated within the IndoPacific warm pool region where deep, moist convection is prevalent, and SST generally exceeds $301 \mathrm{~K}$ yearround. Figure 3 depicts the location of each dataset. The dual-polarimetric S-band radars at Addu City and Kwajalein were, respectively, the S/Ka-band dualpolarimetric, dual-wavelength precipitation radar (S-PolKa) and the Kwajalein Polarimetric S-band Weather Radar (KPOL). The two shipboard radars were C-band radars; neither was dual-polarimetric. All radars scanned a full three-dimensional volume every $10-15 \mathrm{~min}$, and their unambiguous ranges were all approximately $150 \mathrm{~km}$. S-PolKa data were only used to the east of the radar 


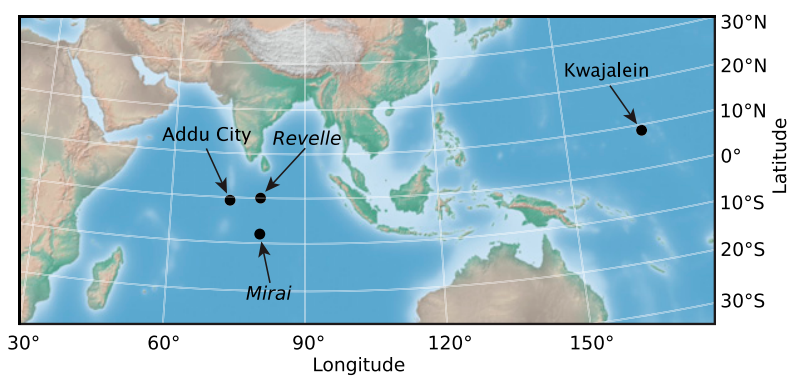

FIG. 3. Map of radar/rawinsonde sites over the Indian and west Pacific Oceans.

because trees to its west blocked the low-elevation beams. All data were quality controlled to remove ground/sea clutter and other potentially spurious echoes, then regridded to a rectilinear grid with $1-\mathrm{km}$ horizontal spacing and 500-m vertical spacing. Rain rates presented herein are domain-averaged rain rates computed using the following Marshall and Palmer (1948) $Z-R$ relationships derived by Thompson et al. (2015) using disdrometer data at Addu City and Manus Island, located in the west Pacific:

$$
Z= \begin{cases}216 R^{1.39}, & \text { all rainfall } \\ 126 R^{1.46}, & \text { convective } \\ 291 R^{1.55}, & \text { stratiform }\end{cases}
$$

Rain-type classification (Powell et al. 2016) was applied to reflectivity data to identify convective, stratiform, and mixed echoes that contained properties of both convective and stratiform precipitation. For the radar data used herein, convective echoes are those with reflectivity $>40-\mathrm{dB} Z$ or echoes that sufficiently exceed the mean reflectivity within a $10-\mathrm{km}$ radius. Mixed echoes are those that surround convective echoes within an up to $10-\mathrm{km}$ radius; they possess latent heating profiles that have peaks in both the upper and lower troposphere-a hybrid of canonical deep convective and stratiform characteristics. Isolated echoes are those with reflectivity $<40 \mathrm{~dB} Z$ within an echo object with size $<2000 \mathrm{~km}^{2}$. Isolated convective core and fringe, respectively, are the rain cores in an isolated echo object and all other surrounding precipitation echo. All other rain echoes not described above are stratiform. The $Z-R$ relationship for all rainfall in Eq. (2) was applied to mixed echoes, and the stratiform $Z-R$ relationship was applied to stratiform and isolated convective fringe echoes. The convective $Z-R$ relationship was applied to convective and isolated convective core echoes. Reflectivity at 2-km altitude was used for all computations herein. To maintain consistency between the S-band and C-band radars, dual-polarimetric variables were not used to estimate rainfall, although the domain-mean rain rates computed using dual-polarimetric variables were similar enough to those computed using only reflectivity to not alter any conclusions.

Rawinsonde data were collected periodically at each location. During DYNAMO, weather balloons were released at each location shown in Fig. 3 every $3 \mathrm{~h}$. At Kwajalein, soundings were typically collected daily at 0000 UTC. The rawinsondes collected vertical profiles of zonal/meridional wind, temperature, and humidity, and from them $\mathrm{CRH}$ was computed. Analysis was only completed on radar data collected within $1.5 \mathrm{~h}$ of a sounding launch. The rawinsonde data represent profiles of point measurements. We cannot be certain that the soundings were entirely representative of conditions throughout the entire radar domain at all times. A direct comparison of rawinsonde data to reanalysis output over the area of the radar domain is not particularly useful because the reanalysis will have assimilated the rawinsonde data, and the result is that the two compare favorably. While the soundings might not represent the environment for all convection within a radar domain, the composite sounding over several thousand radar volumes should capture the large-scale atmospheric features of interest to first order while smoothing out any high-frequency, transient mesoscale vertical structures in the soundings. Additionally, to help alleviate the problem of analyzing soundings that are not representative of the entire radar domain, if during any successive DYNAMO soundings CRH changed by more than 0.1 (e.g., before and after passage of a cold pool or before and during stratiform rainfall, among other possibilities), then both soundings were excluded from analysis.

Large-scale SST and SST gradients were computed in 6-hourly intervals using ERA-Interim (Dee et al. 2011) at $2.5^{\circ} \times 2.5^{\circ}$ grid spacing. One grid point was approximately the size of a radar domain. The SST gradient was computed using first-order centered differencing in both horizontal directions. The SST and gradient at the grid point containing each radar/rawinsonde site was considered at each time a radar volume was analyzed. Reanalysis was used in lieu of observations because satellite-derived SST products do not provide the temporal resolution required to match against radar observations. Mesoscale variability in SST that could be captured with SST datasets of higher spatial resolution is associated with rainfall on spatial scales similar to or smaller than that of a radar domain ( $\mathrm{Li}$ and Carbone 2012; Skyllingstad et al. 2019). The hour-to-hour variability in rainfall on spatial scales smaller than a radar domain, however, is neglected in this study because no data with sufficiently high temporal resolution exists to 
study it, but it could certainly be important for forcing boundary layer convergence and moist convective updrafts at relatively small spatial scales. As of present, the potential role of mesoscale SST variability on promoting high rain rates observed during periods of high CRH would probably be best investigated using a high-resolution coupled ocean-atmosphere model.

\section{Rain rates and radar echo characteristics during moist periods}

Figure 4 depicts rain rate as a function of CRH derived from radar and rawinsonde data. A few near-zero or zero rain rates at $\mathrm{CRH}<0.4$ are not shown. A light blue background covers where $\mathrm{CRH} \in[0.4,0.8)$, and the figure contains a white background elsewhere for $\mathrm{CRH} \geq 0.8$. Each gray dot represents sounding-derived $\mathrm{CRH}$ and the combined time- and domain-mean rain rate (unconditional, including area with zero rain) for each set of radar volumes sampled within $1.5 \mathrm{~h}$ of a sounding launch. The dashed red lines represent the 10th and 90th percentiles of rain rate as a function of $\mathrm{CRH}$. The exponential pickup of the median observed rain rate as a function of increasing $\mathrm{CRH}$ is clear for $\mathrm{CRH}$ up to 0.9 , at which $80 \%$ of observed rain rates ranged between 0.19 and $1.78 \mathrm{~mm} \mathrm{~h}^{-1}$. However, no apparent relationship existed between rain rate and $\mathrm{CRH}$ when $\mathrm{CRH} \geq 0.8$, and when $\mathrm{CRH} \geq 0.8$, the Pearson correlation coefficient between rain rate and CRH was only 0.353. Even when CRH exceeded 0.9, rain rate ranged from near 0 to $\leq 4 \mathrm{~mm} \mathrm{~h}^{-1}$, a range which is essentially identical to that reported by Rushley et al. (2018) using spaceborne microwave retrievals of rain rate over tropical oceans.

Compared to satellite-based retrievals of rainfall, ground-based radar data provides the added benefits of being able to classify the rain types of echoes with high spatial and temporal resolution. Figure 5 shows radardomain mean rain rate as a function of areal coverage of precipitation. Each dot represents a combined time- and domain-mean rain rate for radar volumes obtained within $1.5 \mathrm{~h}$ of the sounding indicating $\mathrm{CRH} \geq 0.8$. The panels include all echo (Fig. 5a), convective and mixed echo (Fig. 5b), stratiform echo (Fig. 5c), and isolated echo (Fig. 5d). In each panel, the fraction of the radar domain experiencing the type of rainfall labeled is denoted on the abscissa. The colors denote the percentage of the radar domain experiencing convective and mixed precipitation; the lightest blue colors indicate $<10 \%$ convective/mixed areal coverage, and black dots denote times when it exceeded $20 \%$. For example, a gray dot in Fig. 5a located near coordinates $\left(0.5,1.0 \mathrm{~mm} \mathrm{~h}^{-1}\right)$ indicates that $50 \%$ of the radar-domain experienced

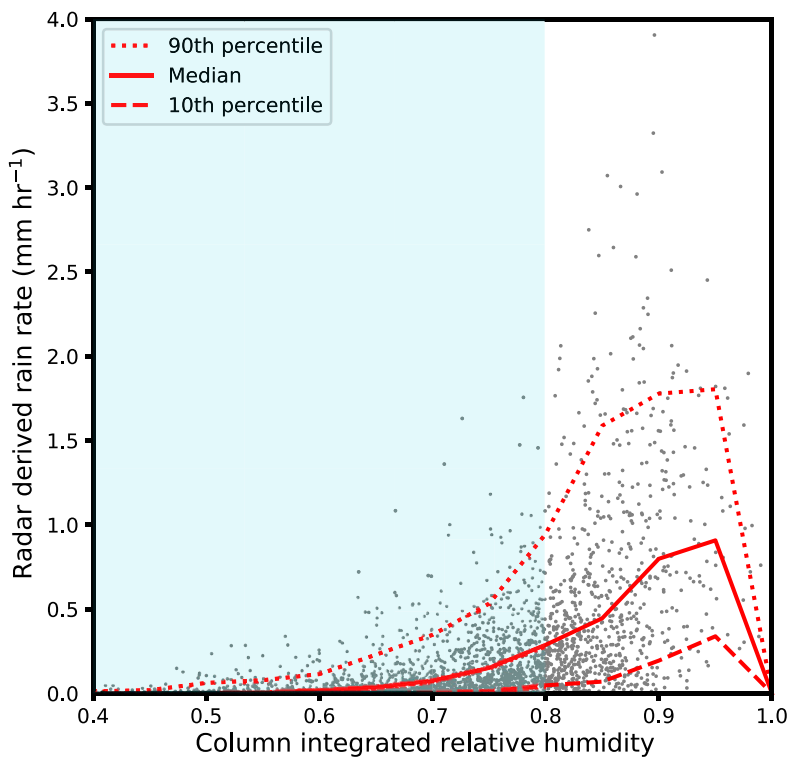

FIG. 4. Scatterplot of rawinsonde-derived CRH (abscissa) and radar-derived 3-hourly time- and domain-mean rain rate $\left(\mathrm{mm} \mathrm{h}^{-1}\right.$; ordinate) for $\mathrm{CRH} \geq 0.4$. The bottom and top dashed lines represent the 10th and 90th percentiles, respectively, of rain rate as a function of $\mathrm{CRH}$, and the solid line denotes the median rain rate. All lines are plotted as a function of $\mathrm{CRH}$ separated into bins with a width of 0.05 . The blue shaded region indicates $\mathrm{CRH}<0.8$.

rainfall of any type, between $10 \%$ and $20 \%$ of the domain experienced convective/mixed rainfall, and the average rain rate within the radar domain was $1.0 \mathrm{~mm} \mathrm{~h}^{-1}$. The largest rain rates, not surprisingly, occurred when the fractional areal coverage of convective echoes was largest (Fig. 5b). Areal coverage of convective rainfall correlated strongly with domain mean rain rate $(95 \%$ confidence interval of $0.924 \leq \rho \leq 0.942)$. Areal coverage of stratiform precipitation was less strongly correlated with domain-mean rain rate $(0.502 \leq \rho \leq 0.599)$. Essentially zero correlation was apparent between areal coverage of isolated precipitation and domain-mean rain rate. When combining all echo regardless of rain type (Fig. 5a), correlation between rainfall areal coverage and domainmean rain rate was $0.760 \leq \rho \leq 0.813$.

Domain-mean rain rates less than $0.5 \mathrm{~mm} \mathrm{~h}^{-1}$ occurred exclusively when the fractional areal coverage of convective rainfall was less than $10 \%$ (Fig. 5a). This happened twice even when the total areal coverage of any type of rainfall exceeded $60 \%$. The panels in Fig. 5 indicate that low fractions of convective areal coverage were observed when $\mathrm{CRH} \geq 0.8$ during at least two occasions: 1) when the radar domain was largely covered in lightly precipitating stratiform precipitation or 2) when the radar domain was largely devoid of any precipitation echo. The first is consistent with rain rate in a radar domain peaking when convection is developing 


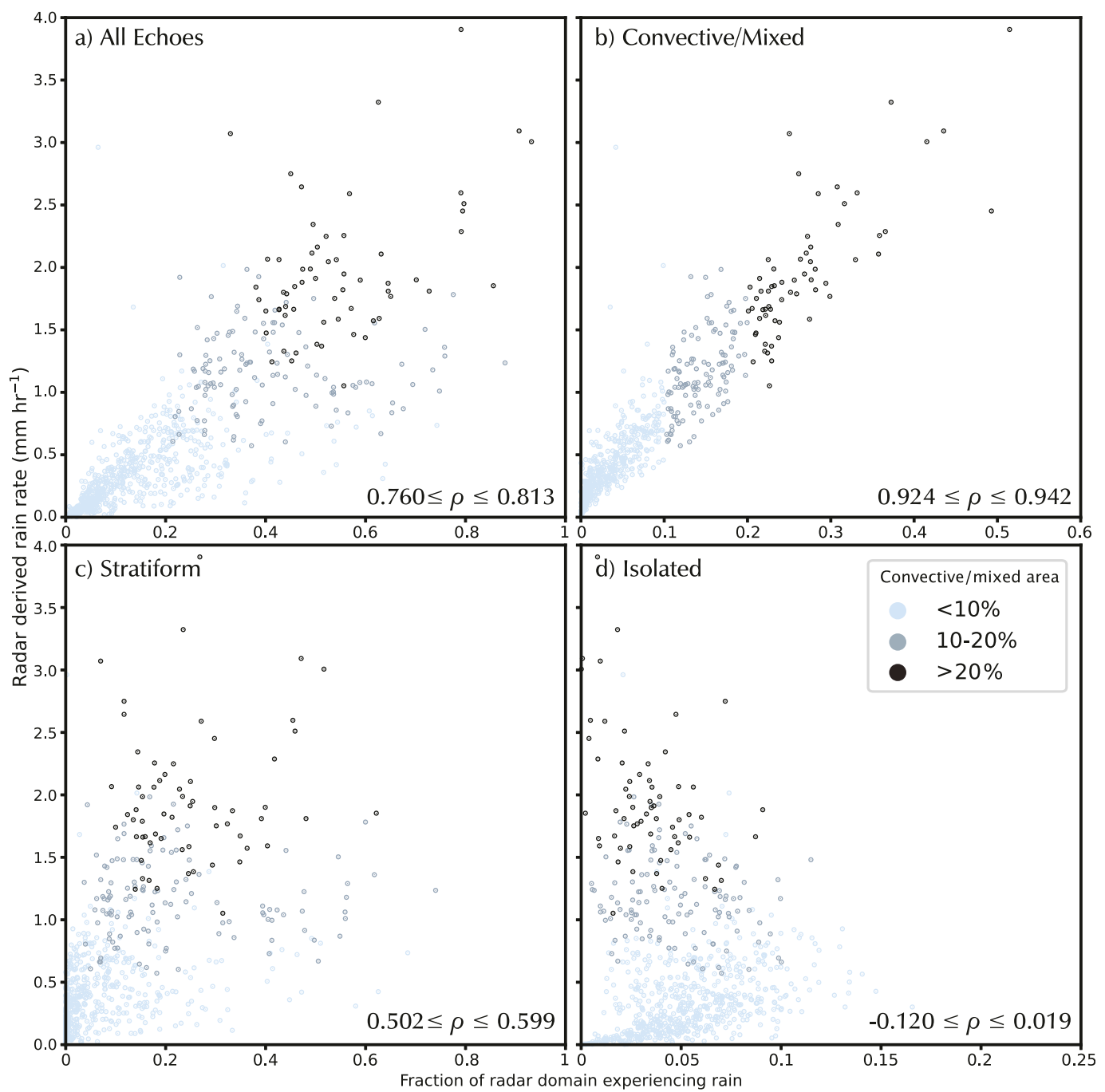

FIG. 5. Scatterplots denoting, on the abscissas, fractions of radar domains experiencing rain of the types indicated in each panel: (a) all raining echoes, (b) convective and mixed echoes, (c) stratiform echoes, and (d) isolated echoes. The ordinate represents 3 -hourly time- and domain-mean rain rate regardless of rain-type classification. Light blue, gray, and black dots respectively indicate 3-hourly periods during which mean combined convective/mixed areal coverage was $<10 \%, 10 \%-20 \%$, and $>20 \%$. The $95 \%$ confidence intervals of Pearson correlation coefficients are shown in the bottom-right corner of each panel. Data are only presented for times when CRH $\geq 0.8$. Note that the abscissas ranges are $[0,1],[0,0.6],[0,1]$, and $[0,0.25]$ for $(a)-(d)$, respectively.

but then decreasing as the convection organizes into an MCS and develops a stratiform precipitation region that contains weaker vertical motions and eventually decays. It highlights the requirement that models accurately represent the life cycle of mesoscale convective systems in order to reproduce the potential range of rain rates that might occur at high CRH.

In support of the first point above, time series of fractional areal coverages of radar echo near these times are shown in Fig. 6. Within $6 \mathrm{~h}$ of times during which stratiform echo fractional areal coverage exceeded $20 \%$ and convective echo fractional areal coverage was less than $5 \%$ (the light blue dots in the bottom center of Fig. 5a), median areal fractions of convective (magenta), stratiform (blue), and isolated (green) echo were computed. Any radar volumes satisfying the $20 \%$ stratiform and $5 \%$ convective fractional areal coverage requirement within $3 \mathrm{~h}$ of each other were considered a single event, and the time $t$ of the first volume in an event was considered the zero time $(t=0)$ for that event. Twenty-one events were recorded: nine each at S-PolKa and KPOL and three at the Revelle. Shaded regions denote the $95 \%$ confidence interval computed using a bootstrapping technique in which 10 events were randomly sampled 


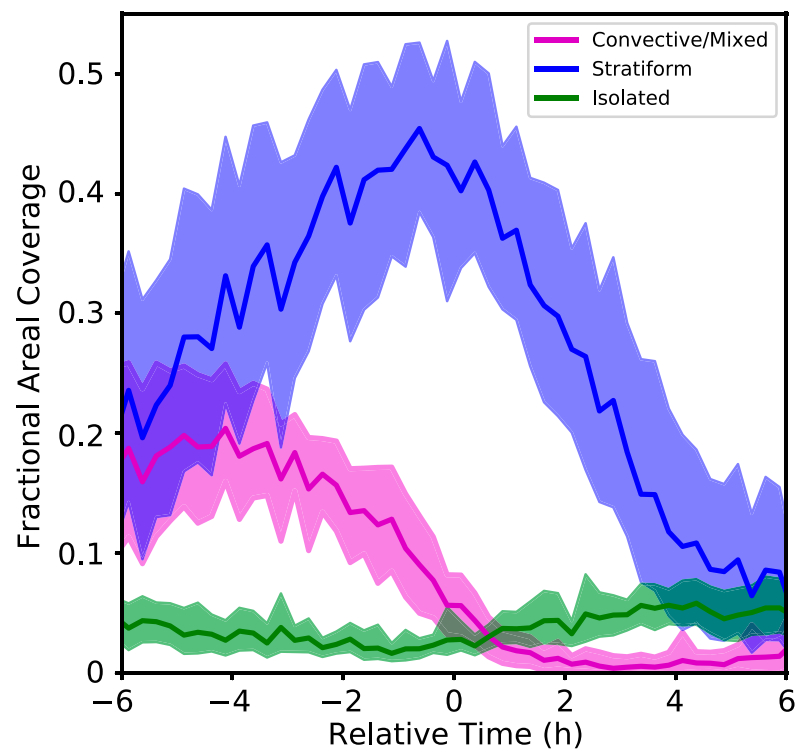

FIG. 6. Lagged time series of convective/mixed (magenta), stratiform (blue), and isolated echo (green) fractional areal coverage in the radar domain for events when stratiform fractional areal coverage exceeded $20 \%$ and convective fractional areal coverage was less than $5 \%$. As described in the text, radar volumes meeting these criteria within $3 \mathrm{~h}$ of one another were all considered part of the same event, and $t=0$ on the abscissa indicates the time of the first radar volume in an event. The shaded regions indicate the $95 \%$ confidence intervals determined via bootstrapping as described in the text.

with replacement 1000 times to compute 1000 potential means at each time. The 2.5 th and 97.5 th percentiles of the 1000 potential means are displayed as the lower and upper bounds, and the 50th percentile is the bold line centered in each shaded area. At $t=0$, stratiform fractional areal coverage was between about $40 \%$ and $50 \%$, while convective fractional areal coverage was around $5 \%$. About $4-6 \mathrm{~h}$ prior to $t=0$, convective fractional areal coverage peaked around $20 \%$, after which it decreased while stratiform fractional areal coverage increased. After $t=0$, convective fractional areal coverage approached zero, while stratiform fractional areal coverage also decreased to about $10 \%$ by $t=+4 \mathrm{~h}$. At all times, fractional areal coverage of isolated echo remained below $10 \%$, and it generally was largest when stratiform fractional areal coverage was low. Such behavior is entirely consistent with convective echo first growing upscale into a mesoscale convective system that contains stratiform precipitation that decays after intense convective updrafts no longer transport water into the upper troposphere. A similar progression of rainfall from convective to stratiform has been observed over the tropical warm pool on many different time scales such as less than $12 \mathrm{~h}$ and $\sim 30$ days (Powell and Houze 2013), 2-4 days (Zuluaga and Houze 2013), and diurnally

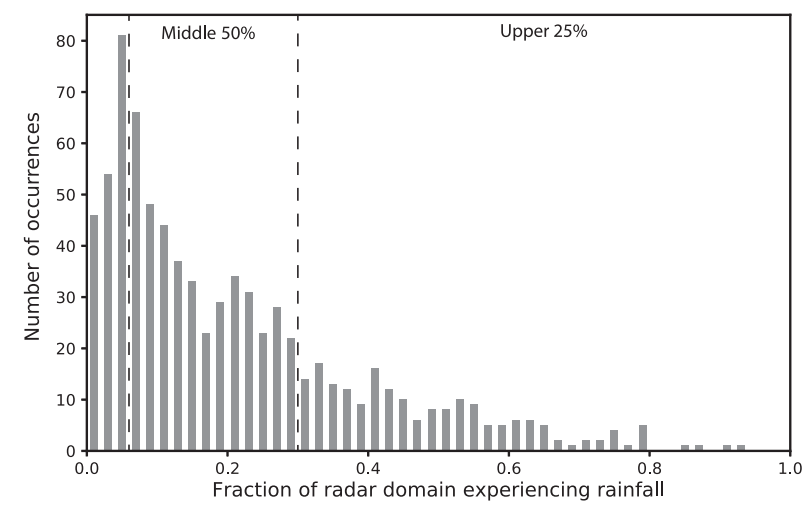

FIG. 7. Histogram of the fraction of the radar domain experiencing rainfall separated into bins with a width of $0.02(2 \%)$. Each instance (total $=791$ ) denoted in the histogram is a 3-hourly mean fractional areal coverage. The two dashed black lines indicate the 25 th and 75 th percentiles of fractional areal coverage, which are about $6 \%$ and $30 \%$, respectively. Data and percentiles are only presented for times when $\mathrm{CRH} \geq 0.8$.

(Sakaeda et al. 2018). It is plausible that rain rates were lower at $\mathrm{CRH}>0.95$ than at $\mathrm{CRH} \approx 0.8-0.9$ because very high CRH only occurred on the mesoscale when mature MCSs consisting of broad, lightly precipitating, stratiform regions were present. More intense rainfall than that observed could also fall in an environment with $\mathrm{CRH}>0.95$, such as in deep convective elements in the core of a mature tropical cyclone. These were not observed in the dataset analyzed herein.

The second point above addresses the fact that sometimes when $\mathrm{CRH} \geq 0.8$, almost no radar echo is observed. This actually happened frequently, and Figs. 1 and 2 provide just one example of cloud cover during such times. Figure 7 illustrates the number of volumes experiencing fractional areal coverage in bins with width of 0.02. For example, the leftmost bar indicates that 46 soundings were obtained when $\mathrm{CRH} \geq 0.8$ and the radar indicated $0 \%-2 \%$ mean areal coverage of rainfall over a 3-h-long period. The modal areal coverage of rainfall was between $4 \%$ and $6 \%$ ( 81 cases), the 25 th percentile was around $6 \%$, and the 75 th percentile was around $30 \%$. The majority of times when $\mathrm{CRH} \geq 0.8$, areal coverage of precipitation echo was less than $20 \%$. By combining Figs. 4, 5, and 7, we conclude that high CRH is a necessary but insufficient condition for intense and/or widespread rainfall to occur on spatial scales of at least the size of a typical precipitation radar domain. Typically, when CRH exceeds $80 \%$, rain was not widespread, and rain rate averaged over an area $150 \mathrm{~km}$ in each horizontal dimension was less than $1.0 \mathrm{~mm} \mathrm{~h}^{-1}$ $\left(24 \mathrm{~mm} \mathrm{day}^{-1}\right)$. Domain-mean rain rates exceeding $2.0 \mathrm{~mm} \mathrm{~h}^{-1}$ sustained for $3 \mathrm{~h}$ were actually quite uncommon, occurring only 24 times between the four 
sites. Again, this result is consistent with that found by Rushley et al. (2018, their Fig. 2b).

The areal coverage of convective echo is directly affected by two quantities: the number and sizes of convective echo objects, which are simply spatially contiguous echoes of convective rain type. Figure 8 depicts how each quantity varied with the convective areal coverage in the radar domain. In Fig. 8, each point represents a separate radar volume and is colored based on the convective (not combined with mixed) area in the volume. A clear relationship existed between domaintotal convective areal coverage and the number of individual convective echo objects plotted along the ordinate $(0.752 \leq \rho \leq 0.770)$. A weaker relationship existed between the mean areal coverage of individual convective echo objects (plotted along the abscissa) and domain-total convective areal coverage $(0.417 \leq \rho \leq 0.453)$. Physically, one possible interpretation of this result is that rain did not increase primarily because convective updrafts and/or rain regions were larger and similar in number. Instead, apparently a larger number of updrafts rooted in the boundary layer became deep enough to support the observed convective areal coverage and rainfall. This result is consistent with recent conclusions reached by Louf et al. (2019) using radar data at Darwin, Australia; however, the distribution of sizes of convective echo objects included objects with area $<500 \mathrm{~km}^{2}$ in their study, which was about an order of magnitude less than in this study, in which convective echo objects were $<70 \mathrm{~km}^{2}$ in area. The difference might be attributed to the difference in the minimum resolvable size of a single data point in our respective datasets $\left[6.25 \mathrm{~km}^{2}\right.$ in Louf et al. (2019) versus $1 \mathrm{~km}^{2}$ herein], making it more likely that the current study identifies separate small convective echoes located near each other.

\section{Environmental associations with low areal coverage of rainfall}

The central hypothesis is that lower-tropospheric characteristics other than moisture content are partially responsible for the vertical growth of convection. Therefore, environmental conditions were assessed at times when areal coverage of convective rainfall was in the upper and lower quartiles of that observed at all times when $\mathrm{CRH} \geq 0.8$. The areal coverages were computed as means within 3-h-long periods surrounding balloon launches. Additionally, to remove rawinsondes potentially launched into mature MCSs, soundings were not considered in this section when the mean stratiform areal coverage within $1.5 \mathrm{~h}$ of sounding launch was at least $10 \%$. The 25 th and 75 th percentiles of convective

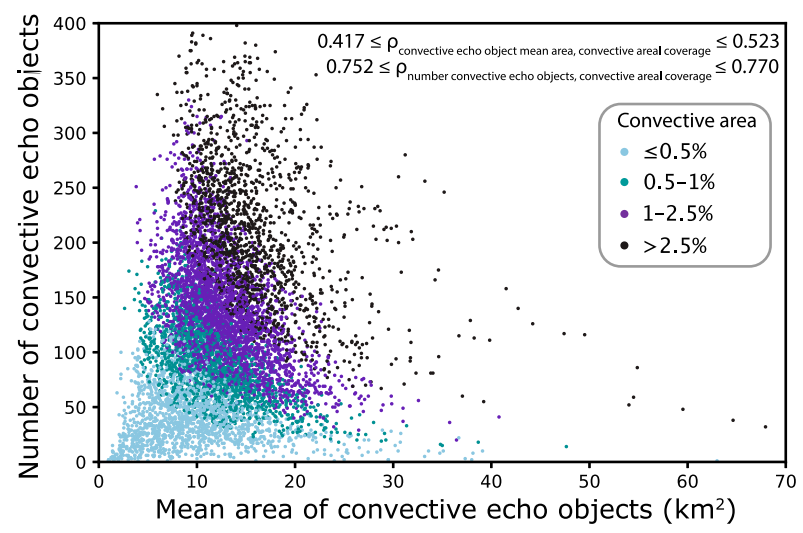

FIG. 8. For all radar volumes observed within $1.5 \mathrm{~h}$ of a sounding launch that indicated $\mathrm{CRH} \geq 0.8$, the mean areal coverage of individual convective echo objects $\left(\mathrm{km}^{2}\right.$; abscissa) plotted against the number of individual convective echo objects (ordinate). Colors in the legend denote areal coverage of convective (not combined with mixed) echo. The $95 \%$ confidence intervals of Pearson correlation coefficients between convective areal coverage and convective echo object mean area (top value) and between convective areal coverage and number of convective echo objects (bottom value) are shown in top-right corner.

areal coverage, respectively, at each DYNAMO site was near $0.5 \%$ and $1.5 \%$ and was near $0.1 \%$ and $0.9 \%$ at Kwajalein. Mean profiles of relative humidity (RH), temperature $(T)$, and zonal $(u)$ and meridional $(v)$ wind were computed from rawinsonde data for times when the radar data indicated convective areal coverage in its upper and lower quartiles. The differences between the profiles for the two quartiles (upper minus lower) are displayed in Fig. 9, Cyan, orange, dark blue, and magenta lines represent the differences between profiles for KPOL, S-PolKa, Revelle, and Mirai, respectively; below these will be referred to as "difference profiles." The numbers in parentheses in the legend denote the independent sample sizes at each site and account for temporal autocorrelation in the rawinsonde data. The black line is a composite across all four radars, and the gray shading represents $95 \%$ confidence intervals. The following discussion will mostly focus on the composited black lines unless otherwise stated.

Mean CRH during times when convective areal coverage was in the upper and lower quartiles was, respectively, $85.6 \%$ and $83.2 \%$. When areal coverage of convective rainfall was in the upper quartile, relative humidity at all levels below $300 \mathrm{hPa}$ was up to $5 \%$ greater than during times the radar experienced lower quartile areal coverage of rain (Fig. 9a). Whether the moister subcloud layer helped lead to widespread convection or was a consequence of its development is unclear, although the lack of any clear relationship between rain rate and $\mathrm{CRH}$ at high values of $\mathrm{CRH}$ in 

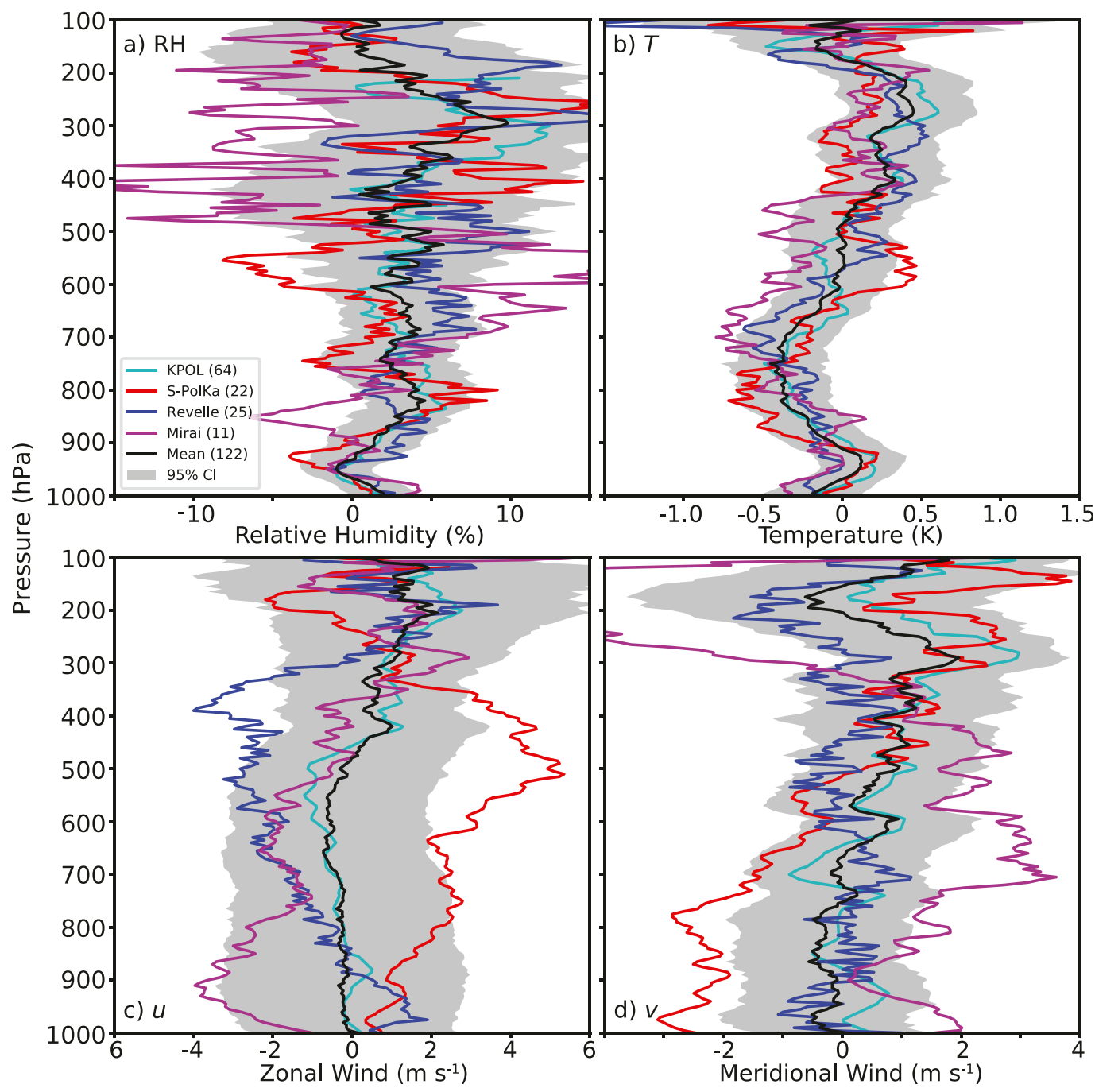

FIG. 9. Difference profiles, as described in the text, of (a) relative humidity (\%), (b) temperature (K), (c) zonal wind $\left(\mathrm{m} \mathrm{s}^{-1}\right)$, and $(\mathrm{d})$ meridional wind $\left(\mathrm{m} \mathrm{s}^{-1}\right)$ between soundings collected when the 3-hourly mean convective echo areal coverage at times within $1.5 \mathrm{~h}$ of a sounding launch was in its upper and lower quartiles and $\mathrm{CRH} \geq 0.8$. Composite profiles of each variable were computed for times when convective areal coverage was in its upper and lower quartiles - calculated separately at each site—and the difference of the two profiles is plotted. Cyan, red, blue, and purple lines indicate results from KPOL, S-PolKa, the R/V Revelle, and the R/V Mirai, respectively. The black line is a weighted mean of all four sites, and the gray shaded area is the $95 \%$ confidence interval around the black line. The number of independent samples for each line is shown in the legend in (a).

Fig. 4 leads the author to speculate that the slightly higher boundary layer CRH indicated by Fig. 9a is probably a consequence of more convection developing. Additionally, at all levels except near $800 \mathrm{hPa}$, the $95 \%$ confidence interval includes zero, and substantial differences existed between the mean difference profiles at the different sites.

The difference in temperature profiles (Fig. 9b) contains perhaps the most compelling result. At around $900 \mathrm{hPa}$, approximately zero difference in temperature was seen between upper- and lower-quartile times. At $700 \mathrm{hPa}$, the environment during upper-quartile periods was about $0.1-0.6 \mathrm{~K}$ cooler. Therefore, the $900-700-\mathrm{hPa}$ (about $1-3 \mathrm{~km}$ ) lapse rate was roughly $0.2 \mathrm{~K} \mathrm{~km}^{-1}$ higher during upper-quartile periods. In other words, much of the environment between the boundary layer and the $0^{\circ} \mathrm{C}$ level was slightly less stable during times when higher areal coverage of convective rainfall (and thus more total rain) occurred. This is consistent with many others who have previously documented how convective inhibition governs the depth of tropical convection (Mapes 2000; Raymond et al. 2003; Kuang 2008). Cooler temperatures were observed beneath about $950 \mathrm{hPa}$ during upper-quartile periods and possibly existed 
because of recent evaporative cooling of precipitation. One caveat is that the difference profiles for temperature are not significantly different from zero at any level; however, the individual profiles from the various sites follow similar patterns, which is not the case for the other variables displayed in Fig. 9. However, Fig. 9b only indicates that the mean lapse rate was larger during times with upper quartile convective areal coverage. The range of $900-700-\mathrm{hPa}$ lapse rates observed during both lower- and upper-quartile periods was about $3.5-6.5 \mathrm{~K} \mathrm{~km}^{-1}$. Figure 10 shows mean rain rate plotted against 900-700-hPa lapse rate (again only when $\mathrm{CRH} \geq 0.8$ ), and no clear linear or nonlinear relationship is apparent. Visually, perhaps a slight positive correlation is apparent, and the Pearson correlation coefficient $(0.031 \leq \rho \leq 0.207)$ is statistically different than zero with $95 \%$ confidence. A similar figure made using instability index from Raymond et al. (2011), which is the difference in mean saturated moist entropy between the 5-7- and 1-3-km layers, on the abscissa instead of 900-700-hPa lapse rate shows an essentially identical result (not shown). Thus, the results suggest that low-tropospheric static stability is just one factorand potentially only a minor factor-that impacts rainfall in moist environments.

Zonal and meridional wind profiles (Figs. 9c,d) show no significant differences; the $95 \%$ confidence intervals include zero at almost all altitudes, and the means do not exceed $\pm 1 \mathrm{~m} \mathrm{~s}^{-1}$ below $300 \mathrm{hPa}$. Although not shown, a profile of the differences in wind magnitude is also close to zero at all pressure levels. Finally, mean SST and SST gradient at each site is analyzed using ERA-Interim output. Table 1 includes the $95 \%$ confidence intervals of SST and SST gradient at each radar site during upper- and lower-quartile periods. Neither SST nor SST gradient were statistically different between upper- and lower-quartile periods at any location. For all locations when $\mathrm{CRH} \geq 0.8$, the mean SST was around $302 \mathrm{~K}$, and the mean SST gradient was between about $0.05-0.19 \mathrm{~K}$ $(100 \mathrm{~km})^{-1}$. Therefore, we conclude that variability in SST on spatial scales of the radar domain or larger does not describe the scatter in rain rates seen in Fig. 4. Therefore, boundary layer convergence driven by SST gradients-at least on the spatial scale of a radar domain - cannot explain the scatter either. The lack of any apparent statistical association between either SST or near-surface wind magnitude with convective areal coverage is a surprising result because it implies that, at least at the mesoscale, surface latent and sensible heat fluxes-which we cannot directly measure-were not associated with convective areal coverage either.

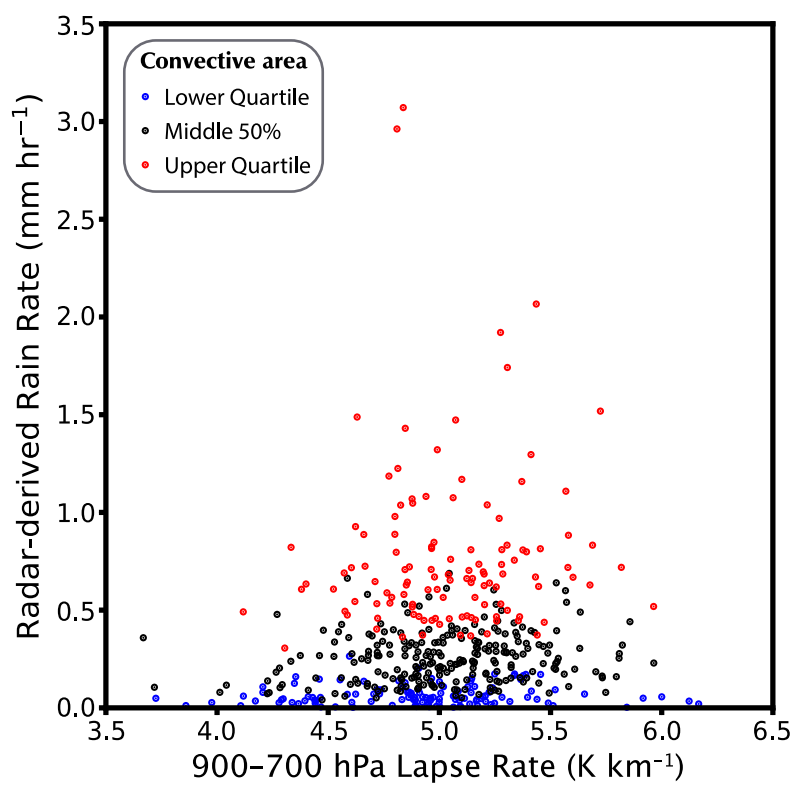

FIG. 10. The $900-700-\mathrm{hPa}$ lapse rate $\left(\mathrm{K} \mathrm{km}^{-1}\right)$ vs 3-h time- and domain-mean rain rate $\left(\mathrm{mm} \mathrm{h}^{-1}\right)$ when $\mathrm{CRH} \geq 0.8$. Blue, black, and red points denote that convective areal coverage was, respectively, in its lower quartile, middle $50 \%$, and upper quartile, which was calculated separately at each site.

\section{Conclusions}

Using radar and rawinsonde datasets over the central Indian Ocean and the west Pacific, we investigated radar echo characteristics and environmental thermodynamic and dynamic profiles during times when columnintegrated relative humidity $(\mathrm{CRH})$ was high. While tropical oceanic rain rate is controlled-to a first orderby environmental humidity, the strong dependence on humidity does not apply at high $\mathrm{CRH}$, especially above $80 \%$. Above this value, mean radar-derived rain rates ranging from $0-50 \mathrm{~mm}$ day $^{-1}$ were observed (Fig. 4), and mean rain rate within a radar domain was strongly linked to the areal coverage of convective echo (Fig. 5), which is consistent with other observational studies in various environmental regimes (e.g., Doneaud et al. 1984; Davies et al. 2013; Louf et al. 2019). Qualitatively speaking, there were two fundamentally different instances in which convective areal coverage was low:

1) when the radar domain was largely covered in weakly precipitating stratiform precipitation associated with a mature and/or decaying mesoscale convective system, and more commonly,

2) when little precipitating echo at all was present within the radar domain.

The first instance points to the importance of accurate representation of convective "organization" and the mesoscale life cycle of convection in models. We also 
TABLE 1. The $95 \%$ confidence intervals of SST (K) and SST gradient $\left(\mathrm{K} \mathrm{km}^{-1}\right)$ for times at which the areal coverage of convective echo in each radar domain was in its lower and upper quartiles during times when stratiform areal coverage was less than $10 \%$. Several significant figures are shown for illustrative purposes only; technically only two to three significant figures are allowable given the small sample size.

\begin{tabular}{|c|c|c|c|c|}
\hline & \multicolumn{2}{|c|}{ SST (K) } & \multicolumn{2}{|c|}{$\Delta \mathrm{SST}\left(\mathrm{K} \mathrm{km}^{-1}\right)$} \\
\hline & Lower quartile & Upper quartile & Lower quartile & Upper quartile \\
\hline S-PolKa & {$[302.38,302.74]$} & {$[301.99,302.43]$} & {$[0.69,1.10] \times 10^{-3}$} & {$[0.48,0.76] \times 10^{-3}$} \\
\hline Mirai & {$[301.70,301.96]$} & {$[301.57,301.88]$} & {$[1.49,2.04] \times 10^{-3}$} & {$[1.27,1.75] \times 10^{-3}$} \\
\hline Revelle & {$[302.43,302.69]$} & {$[302.59,302.79]$} & {$[0.34,0.56] \times 10^{-3}$} & {$[0.48,0.69] \times 10^{-3}$} \\
\hline KPOL & {$[302.28,302.64]$} & {$[302.42,302.75]$} & {$[1.43,1.82] \times 10^{-3}$} & {$[1.22,1.51] \times 10^{-3}$} \\
\hline All sites combined & {$[302.33,302.55]$} & {$[302.35,302.57]$} & {$[1.12,1.41] \times 10^{-3}$} & {$[0.97,1.19] \times 10^{-3}$} \\
\hline
\end{tabular}

concluded that total observed convective area was more dependent upon the number of individual precipitating convective echoes rather the size of convective echo objects (Fig. 8), again consistent with Louf et al. (2019). Therefore, the second instance above begs an answer to the question of why deep, moist convection cannot form in large numbers when the atmosphere is so moist.

2a) Does this happen because the area density of parent thermal updrafts in the boundary layer is time variant and deep convection is limited by the number of viable updrafts?

2b) Alternatively, is the area density of boundary layer thermals over tropical oceans relatively consistent but the free-tropospheric environment permits a smaller fraction of the updrafts to grow strong enough to result in rainfall?

The two above questions cannot be answered without more extensive observations of the subcloud layer beneath, around, and through nascent convective elements, and in the free troposphere surrounding and through shallow, weak convection in its formative stage. If the answer to question $2 b$, however, is affirmative, which is the implicit assumption made in this article, then we expect that characteristics of the lower free troposphere might inhibit or promote deep convection in environments sufficiently moist for widespread deep convection. To gain some insight on what changing environmental properties are associated with the spread in rain rate at high $\mathrm{CRH}$, we evaluated composited vertical profiles of temperature, relative humidity, and zonal/meridional wind only when $\mathrm{CRH}$ exceeded 0.8. This was done when the radar domain was widely covered with convective echo and again when very little convective echo was observed. The differences between the two composite profiles (called difference profiles) for each variable were then interpreted (Fig. 9). This was done only when stratiform areal coverage was less than $10 \%$ within each radar domain to reduce the likelihood that a rawinsonde sampled profiles inside a mesoscale convective system that were not representative of the environment for developing convection. Not surprisingly, since the analysis was completed only when $\mathrm{CRH} \geq 0.8$, the composited relative humidity difference profile composed from a combination of data from all radar sites was near or slightly above zero at all altitudes. Whether these differences were a cause or consequence of deep convection will require additional analysis, possibly including lag-regression analyses of environmental variables against observed rain rate using datasets that are more highly resolved in time. One particularly compelling result was that during periods of high rainfall, the difference profile of temperature indicated an increase in the 900-700-hPa lapse rate of about $0.2-0.4 \mathrm{~K} \mathrm{~km}^{-1}$ (Fig. 9). While this number appears to be small in magnitude, in a moist environment possessing a temperature profile near the saturated adiabat, such small increases in lapse rate could allow updrafts that had been previously unable to reach the $0^{\circ} \mathrm{C}$ level to grow into deeper updrafts. As hypothesized by Holloway and Neelin (2009), once the updrafts rooted in the boundary layer reach the $0^{\circ} \mathrm{C}$ level, the additional release of latent heat by freezing can support their farther upward growth. Our conclusions provide mesoscale observational support to studies (Ahmed and Neelin 2018; Tian and Kuang 2019) indicating the modeled sensitivity of cloud updrafts to low-tropospheric temperature. The variability in temperature profiles observed herein might be attributed to large-scale features such as equatorial waves, or at Kwajalein, also easterly waves. However, the conclusions about the effect of low-level stability on rainfall must be considered with caution: The relationship between 900-700-hPa lapse rate and domain-mean rain rate was weakly linear at best (Fig. 10). This implies that other processesperhaps occurring at scales smaller than what can be easily observed over an entire mesoscale-sized domain-are also important for driving the largest observed rain rates. 
No clear differences in zonal and meridional wind profiles were found between periods of high and low convective areal coverage (and thus rainfall at high $\mathrm{CRH}$ ); however, substantial variability between individual soundings at the various radar sites was observed. A larger sample size is required to make any final conclusion regarding the effect of wind profiles on rain rate; furthermore, the influence may differ by time and location. At least two different physical processes could link wind to rain rate: near-surface wind might alter surface heating and moisture fluxes, and strong low-level wind shear might weaken nascent updrafts. Finally, while tropical sea surface temperature (SST) gradients are known to influence boundary layer convergence on large scales (Back and Bretherton 2009a,b), neither SST nor SST gradients derived from reanalysis-and therefore surface air-sea fluxes-were found to impact rainfall when $\mathrm{CRH} \geq 0.8$ on the spatial scales studied herein (Table 1). However, we caution that sensitivity of convection to energy flux from ocean to atmosphere or the small-scale areas of SST-driven convergence may be important on spatial scales much smaller than what we can capture using a single sounding and rain-rate averaged over a $\sim 70000-\mathrm{km}^{2}$ radar domain and on temporal scales much faster than the 3-24-h intervals at which atmospheric soundings were obtained ( $\mathrm{Li}$ and Carbone 2012; Skyllingstad et al. 2019). High-resolution threedimensional observations of the precipitating and nonprecipitating cloud population, as well as spatially distributed observations of the boundary layer and ocean surface will ultimately be needed to adequately explore the relationship between surface fluxes and deep convection.

Of course, this study is strewn with at least as many caveats as conclusions. Foremost, the observations are spatially limited, and the spatial scales of the radar and rawinsonde data are unavoidably incompatible. The rawinsonde data essentially represent a single vertical profile of the atmosphere. Meanwhile, the radar-derived rain rates represent precipitation in an area up to $\sim 70000 \mathrm{~km}^{2}$. In extreme cases, the sounding could sample, for example, a dry environment surrounded by precipitation or a very moist environment in an isolated convective region situated in an otherwise dry environment. However, most of the time in the tropics, even when the environment is moist, little precipitation echo was observed (Fig. 6). This means that most soundings probably captured the salient characteristics of the large-scale environment outside clouds and included some mesoscale variability of lower magnitude superimposed onto the large-scale components of each sounding. Therefore, the relatively few soundings that captured dynamic and thermodynamic profiles that were not representative of the entire radar domain should not greatly impact our composited results in an adverse way if our sample size is sufficient, and any lowmagnitude mesoscale variability included in individual soundings should get smoothed out by a composite.

Our second problem, however, is that the number of independent samples-after accounting for temporal autocorrelation of radar and rawinsonde data-is actually quite small, even when analyzing about 3 months of data at three locations over the Indian Ocean and about 4 years of data from Kwajalein Atoll. One possible remedy is to incorporate additional larger, long-term datasets in the tropics, such as the $\sim 25$-yr-long radar and rawinsonde datasets from Guam or those other sites outside of the Indo-Pacific warm pool such as at Hawaii or South Florida and the Caribbean. However, using just ground-based radar data limits us to drawing conclusions about how rain rate is affected by the environment on the mesoscale. Relationships between the large-scale environment and rain rate at much larger spatial scales may be very similar. Utilization of satellite data, such as TRMM and GPM for precipitation and GPS radio occultation measurements for thermodynamic profiles, will increase sample size and provide a means for determining if rain rate is affected any differently at spatial scales larger than a typical S- or C-band radar domain.

An equally important caveat is that our conclusions only present associations of rain rate with variables that can be measured in situ with sensors tethered to a weather balloon. However, tropical marine convection is rooted in the boundary layer below the lifting condensation level near $950 \mathrm{hPa}$. To move toward unraveling a likely complicated path of causality to heavy rainfall over tropical oceans, a detailed modeling study will be required to test the sensitivity of convection to small-scale variability in temperature, humidity, and wind in the boundary layer and lower free troposphere. To some extent, this work has been partially done (section 1). However, a proper modeling study must account for the variability in the structures of buoyant tropical updrafts. To do this, we must observe-at spatial scales of tens of meters or less-what real marine convection looks like in its early stages. For example, what is the distribution of the widths of real thermal updrafts? How far away from updrafts are they from the environments from which they entrain air? Are there differences in the characteristics of updrafts that grow into deep elements and those that do not, and if so, on what do these updraft properties depend? These questions cannot be answered with the tools used in this paper. Instrumentation like cloud radars, lidars, and direct in situ aircraft observations will be required in the boundary layer and in the lower free troposphere in and around shallow convection. 
High-resolution satellite imagery (i.e., no coarser than a few tens of meters) might also be leveraged to put such observations into a broader context. Field efforts like Elucidating the Role of Cloud-Circulation Coupling in Climate (EUREC4A) and the Next-Generation Aircraft Remote Sensing for Validation Studies (NARVAL)/NARVAL2, which have operated in largely convectively suppressed tropical environments in the Atlantic near the Barbados Cloud Observatory (Stevens et al. 2016), might provide a blueprint for how to collect some of these measurements in a deep convective tropical regime.

Acknowledgments. S. Powell was supported by Research Initiation Program funding from the Naval Postgraduate School. Early versions of the work were also done while the author was supported by a NOAA Climate and Global Change Postdoctoral Fellowship, sponsored by UCAR's Cooperative Programs for the Advancement of Earth System Science.

\section{REFERENCES}

Ahmed, F., and C. Schumacher, 2015: Convective and stratiform components of the precipitation-moisture relationship. Geophys. Res. Lett., 42, 10 453-10 462, https://doi.org/ 10.1002/2015GL066957.

__ , and J. D. Neelin, 2018: Reverse engineering the tropical precipitation-buoyancy relationship. J. Atmos. Sci., 75, 1587-1608, https://doi.org/10.1175/JAS-D-17-0333.1.

Alishouse, J. C., 1983: Total precipitable water and rainfall determinations from the SEASAT scanning multichannel microwave radiometer. J. Geophys. Res. Oceans, 88, 1929-1935, https://doi.org/10.1029/JC088iC03p01929.

Anber, U., S. Wang, and A. H. Sobel, 2014: Response of atmospheric convection to vertical wind shear: Cloud-resolving simulations with parameterized large-scale circulation. Part I: Specified radiative cooling. J. Atmos. Sci., 71, 2976-2993, https://doi.org/10.1175/JAS-D-13-0320.1.

Back, L. E., and C. S. Bretherton, 2009a: On the relationship between SST gradients, boundary layer winds, and convergence over the tropical oceans. J. Climate, 22, 4182-4196, https:// doi.org/10.1175/2009JCLI2392.1.

—_, and — , 2009b: A simple model of climatological rainfall and vertical motion patterns over the tropical oceans. J. Climate, 22, 6477-6497, https://doi.org/10.1175/ 2009JCLI2393.1.

Bretherton, C. S., M. E. Peters, and L. E. Back, 2004: Relationships between water vapor path and precipitation over the tropical oceans. J. Climate, 17, 1517-1528, https://doi.org/10.1175/ 1520-0442(2004)017<1517:RBWVPA > 2.0.CO;2.

Brown, R. G., and C. Zhang, 1997: Variability of midtropospheric moisture and its effect on cloud-top height distribution during TOGA COARE. J. Atmos. Sci., 54, 2760-2774, https://doi.org/ 10.1175/1520-0469(1997)054<2760:VOMMAI > 2.0.CO;2.

Chikira, M., 2010: A cumulus parameterization with statedependent entrainment rate. Part II: Impact on climatology in a general circulation model. J. Atmos. Sci., 67, 2194-2211, https://doi.org/10.1175/2010JAS3317.1.
Davies, L., C. Jakob, P. May, V. V. Kumar, and S. Xie, 2013: Relationships between the large-scale atmosphere and the smallscale convective state for Darwin, Australia. J. Geophys. Res. Atmos., 118, 11 534-11 545, https://doi.org/10.1002/jgrd.50645.

Dee, D. P., and Coauthors, 2011: The ERA-Interim reanalysis: Configuration and performance of the data assimilation system. Quart. J. Roy. Meteor. Soc., 137, 553-597, https://doi.org/ 10.1002/qj.828.

Derbyshire, S. H., I. Beau, P. Bechtold, J.-Y. Grandpeix, J.-M. Piriou, J.-L. Redelsperger, and P. M. M. Soares, 2004: Sensitivity of moist convection to environmental humidity. Quart. J. Roy. Meteor. Soc., 130, 3055-3079, https://doi.org/10.1256/ qj.03.130.

Doneaud, A., S. Ionescu-Niscov, D. L. Priegnitz, and P. L. Smith, 1984: The area-time integral as an indicator for convective rain volumes. J. Climate Appl. Meteor., 23, 555-561, https://doi.org/ 10.1175/1520-0450(1984)023<0555:TATIAA $>2.0 . C O ; 2$.

Frenkel, Y., A. J. Majda, and B. Khouider, 2013: Stochastic and deterministic multicloud parameterizations for tropical convection. Climate Dyn., 41, 1527-1551, https://doi.org/10.1007/ s00382-013-1678-z.

Holloway, C. E., and J. D. Neelin, 2009: Moisture vertical structure, column water vapor, and tropical deep convection. J. Atmos. Sci., 66, 1665-1683, https://doi.org/10.1175/2008JAS2806.1.

— , and - 2010: Temporal relations of column water vapor and tropical precipitation. J. Atmos. Sci., 67, 1091-1105, https://doi.org/10.1175/2009JAS3284.1.

Kuang, Z., 2008: A moisture-stratiform instability for convectively coupled waves. J. Atmos. Sci., 65, 834-854, https://doi.org/ 10.1175/2007JAS2444.1.

Kuo, Y.-H., J. D. Neelin, and C. R. Mechoso, 2017: Tropical convective transition statistics and causality in the water vapor-precipitation relation. J. Atmos. Sci., 74, 915-931, https://doi.org/10.1175/JAS-D-16-0182.1.

_ , K. A. Schiro, and J. D. Neelin, 2018: Convective transition statistics over tropical oceans for climate model diagnostics: Observational baseline. J. Atmos. Sci., 75, 1553-1570, https:// doi.org/10.1175/JAS-D-17-0287.1.

Li, Y., and R. E. Carbone, 2012: Excitation of rainfall over the tropical western Pacific. J. Atmos. Sci., 69, 2983-2994, https:// doi.org/10.1175/JAS-D-11-0245.1.

Liu, C., and M. W. Moncrieff, 2001: Cumulus ensembles in shear: Implications for parameterization. J. Atmos. Sci., 58, 2832-2842, https://doi.org/10.1175/1520-0469(2001) $058<2832$ : CEISIF $>2.0$.CO;2.

Louf, V., C. Jakob, A. Protat, M. Bergemann, and S. Narsey, 2019: The relationship of cloud number and size with their largescale environment in deep tropical convection. Geophys. Res. Lett., 46, 9203-9212. https://doi.org/10.1029/2019GL083964.

Mapes, B. E., 2000: Convective inhibition, subgrid-scale triggering energy, and stratiform instability in a toy tropical wave model. J. Atmos. Sci., 57, 1515-1535, https://doi.org/10.1175/ 1520-0469(2000)057<1515:CISSTE $>2.0$. CO;2.

_ E. S. Chung, W. M. Hannah, H. Masunaga, A. J. Wimmers, and C. S. Velden, 2018: The meandering margin of the meteorological moist tropics. Geophys. Res. Lett., 45, 1177-1184, https://doi.org/10.1002/2017GL076440.

Marshall, J. S., and W. M. Palmer, 1948: The distribution of raindrops with size. J. Meteor., 5, 165-166, https://doi.org/10.1175/ 1520-0469(1948)005<0165:TDORWS > 2.0.CO;2.

Moncrieff, M. W., 1981: A theory of organized steady convection and its transport properties. Quart. J. Roy. Meteor. Soc., 107, 29-50, https://doi.org/10.1002/qj.49710745103. 
Muller, C. J., L. E. Back, P. A. O'Gorman, and K. A. Emanuel, 2009: A model for the relationship between tropical precipitation and column water vapor. Geophys. Res. Lett., 36, L16804, https://doi.org/10.1029/2009GL039667.

NASA, 2014: Global Precipitation Measurement radar data. Subset used: QC UF Radar Data for Kwajalein (KPOL), NASA GSFC, accessed 21 May 2019, https:/gpm-gv.gsfc.nasa.gov/ Radar/index.html.

NOAA/ESRL, 2009: NOAA/ESRL radiosonde database (updated daily). Station Identifier 91366, NOAA, accessed 21 May 2019, https://ruc.noaa.gov/raobs/.

Peters, J. M., W. Hannah, and H. Morrison, 2019: The influence of vertical wind shear on moist thermals. J. Atmos. Sci., 76, 1645-1659, https://doi.org/10.1175/JAS-D-18-0296.1.

Peters, K., C. Jakob, L. Davies, B. Khouider, and A. J. Majda, 2013: Stochastic behavior of tropical convection in observations and a multicloud model. J. Atmos. Sci., 70, 3556-3575, https:// doi.org/10.1175/JAS-D-13-031.1.

Peters, O., and J. D. Neelin, 2006: Critical phenomena in atmospheric precipitation. Nat. Phys., 2, 393-396, https://doi.org/ 10.1038/nphys 314 .

Powell, S. W., and R. A. Houze, 2013: The cloud population and onset of the Madden-Julian Oscillation over the Indian Ocean during DYNAMO-AMIE. J. Geophys. Res. Atmos., 118, 11 979-11 995, https://doi.org/10.1002/2013JD020421.

,-- , and S. R. Brodzik, 2016: Rainfall-type categorization of radar echoes using polar coordinate reflectivity data. J. Atmos. Oceanic Technol., 33, 523-538, https://doi.org/10.1175/ JTECH-D-15-0135.1.

Raymond, D. J., 2007: Thermodynamic control of tropical rainfall. Quart. J. Roy. Meteor. Soc., 126, 889-898, https://doi.org/10.1002/ qj. 49712656406.

— tropical oceans from environmental conditions. J. Adv. Model. Earth Syst., 8, 703-718, https://doi.org/10.1002/2015MS000595.

— , G. B. Raga, C. S. Bretherton, J. Molinari, C. López-Carrillo, and Ž. Fuchs, 2003: Convective forcing in the intertropical convergence zone of the eastern Pacific. J. Atmos. Sci., 60, 2064-2082, https://doi.org/10.1175/1520-0469(2003) $060<2064$ :CFITIC $>2.0$. CO 2 .

_ - S. L. Sessions, and C. López-Carrillo, 2011: Thermodynamics of tropical cyclogenesis in the northwest Pacific. J. Geophys. Res., 116, D18101, https://doi.org/10.1029/2011JD015624.

Redelsperger, J.-L., D. B. Parsons, and F. Guichard, 2002: Recovery processes and factors limiting cloud-top height following the arrival of a dry intrusion observed during TOGA COARE. J. Atmos. Sci., 59, 2438-2457, https://doi.org/10.1175/ 1520-0469(2002)059<2438:RPAFLC $>2.0 . \mathrm{CO} ; 2$.

Romps, D. M., and Z. Kuang, 2011: A transilient matrix for moist convection. J. Atmos. Sci., 68, 2009-2025, https://doi.org/ 10.1175/2011JAS3712.1.

Rushley, S. S., D. Kim, C. S. Bretherton, and M.-S. Ahn, 2018: Reexamining the nonlinear moisture-precipitation relationship over the tropical oceans. Geophys. Res. Lett., 45, 1133-1140, https://doi.org/10.1002/2017GL076296.

Sahany, S., J. D. Neelin, K. Hales, and R. B. Neale, 2012: Temperaturemoisture dependence of the deep convective transition as a constraint on entrainment in climate models. J. Atmos. Sci., 69, 1340-1358, https://doi.org/10.1175/JAS-D-11-0164.1.

Sakaeda, N., S. W. Powell, J. Dias, and G. N. Kiladis, 2018: The diurnal variability of precipitating cloud populations during
DYNAMO. J. Atmos. Sci., 75, 1307-1326, https://doi.org/ 10.1175/JAS-D-17-0312.1.

Schiro, K. A., and J. D. Neelin, 2019: Deep convective organization, moisture vertical structure, and convective transition using deep-inflow mixing. J. Atmos. Sci., 76, 965-987, https:// doi.org/10.1175/JAS-D-18-0122.1.

Sherwood, S. C., 1999: Convective precursors and predictability in the tropical western Pacific. Mon. Wea. Rev., 127, 2977-2991, https://doi.org/10.1175/1520-0493(1999)127<2977:CPAPIT> 2.0.CO;2.

_ and R. Wahrlich, 1999: Observed evolution of tropical deep convective events and their environment. Mon. Wea. Rev., 127, 1777-1795, https://doi.org/10.1175/1520-0493(1999) $127<1777$ :OEOTDC $>2.0 . \mathrm{CO} ; 2$.

Skyllingstad, E. D., S. P. de Szoeke, and L. W. O'Neill, 2019: Modeling the transient response of tropical convection to mesoscale SST variations. J. Atmos. Sci., 76, 1227-1244, https:// doi.org/10.1175/JAS-D-18-0079.1.

Sobel, A. H., S. E. Yuter, C. S. Bretherton, and G. N. Kiladis, 2004: Large-scale meteorology and deep convection during TRMM KWAJEX. Mon. Wea. Rev., 132, 422-444, https://doi.org/ 10.1175/1520-0493(2004)132<0422:LMADCD > 2.0.CO;2.

Song, X., and G. J. Zhang, 2009: Convection parameterization, tropical pacific double ITCZ, and upper-ocean biases in the NCAR CCSM3. Part I: Climatology and atmospheric feedback. J. Climate, 22, 4299-4315, https://doi.org/10.1175/ 2009JCLI2642.1.

Stechmann, S. N., and J. D. Neelin, 2011: A stochastic model from the transition to strong convection. J. Atmos. Sci., 68 , 2955-2970, https://doi.org/10.1175/JAS-D-11-028.1.

Stevens, B., and Coauthors, 2016: The Barbados Cloud Observatory: Anchoring investigations of clouds and circulation on the edge of the ITCZ. Bull. Amer. Meteor. Soc., 97, 787-801, https://doi.org/10.1175/BAMS-D-14-00247.1.

Thompson, E. J., S. A. Rutledge, B. Dolan, and M. Thurai, 2015: Drop size distributions and radar observations of convective and stratiform rain over the equatorial Indian and West Pacific oceans. J. Atmos. Sci., 72, 4091-4125, https://doi.org/10.1175/ JAS-D-14-0206.1.

Tian, Y., and Z. Kuang, 2019: Why does deep convection have different sensitivities to temperature perturbations in the lower versus upper troposphere? J. Atmos. Sci., 76, 27-41, https://doi.org/10.1175/JAS-D-18-0023.1.

UCAR, 2017: DYNAMO legacy dataset access. Accessed 21 May 2019, http://dynamo.ml-ext.ucar.edu/dynamo_legacy/.

Wang, S., and A. H. Sobel, 2011: Response of convection to relative sea surface temperature: Cloud-resolving simulations in two and three dimensions. J. Geophys. Res., 116, D11119, https:// doi.org/10.1029/2010JD015347.

, and - 2012: Impact of imposed drying on deep convection in a cloud-resolving model. J. Geophys. Res., 117, D02112, https://doi.org/10.1029/2011JD016847.

Yoneyama, K., C. Zhang, and C. N. Long, 2013: Tracking pulses of the Madden-Julian oscillation. Bull. Amer. Meteor. Soc., 94, 1871-1891, https://doi.org/10.1175/BAMS-D-12-00157.1.

Zuluaga, M. D., and R. A. Houze Jr., 2013: Evolution of the population of precipitating convective systems over the equatorial Indian Ocean in active phases of the Madden-Julian oscillation. J. Atmos. Sci., 70, 2713-2725, https://doi.org/10.1175/ JAS-D-12-0311.1. 